\title{
Mikroplastik w środowisku naturalnym
}

\author{
Katarzyna Samsonowska ${ }^{1)}{ }^{*)}$ (ORCID ID: 0000-0002-4381-2223), Alicja Kaszuba ${ }^{1)}$
}

DOI: dx.doi.org/10.14314/polimery.2022.1.4

\begin{abstract}
Streszczenie: Ze wzrostem produkcji tworzyw polimerowych gwałtownie zwiększyła się ilość odpadów plastikowych. Problem dotyczy nie tylko akwenów, gdzie odpady z tworzyw tworzą dryfujące wyspy śmieci, ale także plaż i niekontrolowanych wysypisk. Realnym niebezpieczeństwem dla środowiska naturalnego oraz zdrowia ludzi i zwierząt jest tzw. mikroplastik.
\end{abstract}

Słowa kluczowe: odpady tworzyw sztucznych, mikroplastik, akty prawne.

\section{Microplastic}

\begin{abstract}
With the increase in plastic production, the amount of plastic waste has increased sharply. The problem concerns not only waters where plastic waste forms drifting islands of rubbish, but also beaches and uncontrolled landfills. The real danger to the environment and human and animal health is the so-called microplastic.
\end{abstract}

Keywords: polymers waste, microplastics, legal acts.

Tworzywa polimerowe, wynalezione w XIX w. przez Aleksandra Parksa, od lat 50. XX w. towarzyszą człowiekowi w każdej dziedzinie życia, począwszy od przedmiotów codziennego użytku, a kończąc na skomplikowanych procesach technologicznych. Ich zastosowanie na ogół wynika z przesłanek ekonomicznych, a w niektórych wypadkach jest jedynym możliwym rozwiązaniem. Ze wzrostem produkcji tworzyw polimerowych gwałtownie rośnie ilość ich odpadów. Pomimo, że duża część tych odpadów poddawana jest recyklingowi energetycznemu (spalanie), chemicznemu (piroliza, depolimeryzacja) i mechanicznemu (segregacja i powtórne przetwórstwo), znaczna ich ilość trafia na wysypiska. $Z$ uwagi na długotrwały proces rozpadu zalegające odpady $z$ tworzyw stanowią poważne zagrożenie dla środowiska naturalnego. Problem dotyczy nie tylko akwenów, gdzie odpady polimerowe tworzą dryfujące wyspy śmieci, ale także plaż i tzw. „dzikich" wysypisk. Szczególnie dużym wyzwaniem są mikrocząstki tworzyw polimerowych (mikroplastik) obecne w środowisku, a także w żywności.

\section{PRODUKCJA TWORZYW SZTUCZNYCH}

Tworzywa polimerowe są wytwarzane $\mathrm{w}$ procesie polimeryzacji addycyjnej (np. polietylen) lub kondensa-

\footnotetext{
1) Sieć Badawcza Łukasiewicz - Instytut Biopolimerów i Włókien Chemicznych Oddział w Warszawie COBRO - Centrum Badawczo-Rozwojowe Opakowań, ul. Konstancińska 11, 02-942 Warszawa.

*) Autor do korespondencji:

katarzyna.samsonowska@ibwch.lukasiewicz.gov.pl
}

cyjnej (np. poliamid). Do ich produkcji stosuje się substancje pomocnicze, takie jak: pigmenty, plastyfikatory, stabilizatory, antyutleniacze i napełniacze, które mają wpływ na zmianę właściwości chemicznych i użytkowych danego materiału. Tworzywa polimerowe dzieli się na termoplastyczne, np. poliolefiny, poli(tereftalan etylenu), polistyren, poli(chlorek winylu), poliwęglan, poliamid, lub chemo- $\mathrm{i}$ termoutwardzalne (poliuretany, żywice epoksydowe). Termoplasty w podwyższonej temperaturze ulegają uplastycznieniu i mogą być przetwarzane różnymi metodami (wytłaczanie, wtryskiwanie, termoformowanie, kalandrowanie). Proces ten jest odwracalny, dlatego tworzywa termoplastyczne są stosunkowo łatwe w recyklingu. Natomiast termoutwardzalne ze względu na usieciowanie są trudne $\mathrm{w}$ recyklingu.

$\mathrm{W}$ ostatnich latach duże zainteresowanie wzbudzają materiały (bio)degradowalne. Są to tworzywa otrzymywane z surowców odnawialnych lub petrochemicznych, ulegające rozkładowi pod wpływem działania światła, wody i/lub mikroorganizmów (bakterii). Niektóre z tych tworzyw (PLA) ulegają biodegradacji dopiero w temperaturze powyżej $50^{\circ} \mathrm{C}, \mathrm{w}$ warunkach kompostowania przemysłowego, nie zaś w środowisku naturalnym. Inne zawierają w swoim składzie prooksydanty, które powodują defragmentację tworzywa, a nie jego biodegradację. Produkcja tego typu tworzyw została zakazana kilka lat temu, ale nadal mogą znajdować się w środowisku i stanowić potencjalne źródło mikroplastiku. Są też polimery rozkładające się w środowisku wodnym, np. poli(hydroksy maślan) (PHA).

Największym odbiorcą tworzyw polimerowych jest przemysł opakowaniowy (40\%), następnie sektor budow- 
lany (20\%), branża motoryzacyjna $(9 \%)$, gospodarstwa domowe (4\%), przemysł rolniczy (3\%) i inne branże (17\%) [1]. Szczególnie duże ilości opakowań zużywa przemysł spożywczy i kosmetyczny. Prognozy przewidują, że ze względu na wzrost populacji na świecie oraz nawyki konsumpcyjne w 2025 r. produkcja tworzyw podwoi się, a w 2050 r. wzrośnie trzykrotnie [2]. Średnie zużycie opakowań na mieszkańca Unii Europejskiej wynosi ok. 180 kg, a w Polsce ok. 160 kg. Według szacunków ilość wytwarzanych w UE odpadów wynosi ok. 30 mld t/r i tylko $40 \%$ odpadów pochodzących z gospodarstw domowych poddawanych jest recyklingowi [1].

\section{CO TO JEST MIKROPLASTIK?}

Obecnie nie ma jednolitej definicji mikroplastiku. W badaniach przeprowadzonych przez EFSA (European Food Safety Authority) przyjęto następującą definicję: mikroplastik (MP) to heterogeniczna mieszanina różnego kształtu materiatów w postaci fragmentów, włókien, elipsoid, granulek, śrutu, płatków o wielkości w zakresie od 0,1 $\mu m$ do $5 \mathrm{~mm}$. Cząstki o mniejszej średnicy są zaliczane do nanoplastiku [3].

Ze względu na pochodzenie wyróżnia się mikroplastik pierwotny i wtórny. Mikroplastik pierwotny to proszki i mikrogranulaty polimerowe obecne m.in. w produktach kosmetycznych (kremy, peelingi, żele do mycia, szampony, pasty do zębów itp.) oraz środkach czyszczących (chemia gospodarcza i przemysłowa). Są one dodawane w celu poprawy właściwości fizykochemicznych, np. gęstości, stabilności, właściwości ściernych. Mogą być również nośnikiem substancji zapachowych, środków nawilżających lub innych składników aktywnych.

Mikroplastik wtórny powstaje w wyniku degradacji i fragmentacji tworzyw polimerowych. Fragmentacja może być następstwem używania materiałów syntetycznych, np. ścieranie się ubrań, opon, obuwia. Może też być wynikiem erozji mechanicznej (działanie wiatru, wody, piasku, żwiru, fal morskich) lub starzenia tworzywa polimerowego pod wpływem warunków atmosferycznych (temperatura, promieniowanie UV). Mikrocząstki polimerowe mogą być również uwalniane podczas produkcji przedmiotów z tworzyw sztucznych. Mikroplastik wtórny stanowi ok. 70-80\% mikroplastiku pływającego w morzach i oceanach.

\section{MIKROPLASTIK W ŚRODOWISKU NATURALNYM}

Mikrocząstki polimerowe różnią się właściwościami fizycznymi i chemicznymi (wielkość, skład, masa, gęstość, kształt, kolor). Właściwości te decydują o zachowaniu się mikroplastiku w środowisku naturalnym, np. migracji, tworzeniu dyspersji i jej stabilności, sorpcji zanieczyszczeń, zasiedlaniu przez mikroorganizmy oraz biodostępności i toksyczności. Unoszące się na powierzchni wód cząstki o małej gęstości są bardziej podatne na transport adwek- cyjny niż cząstki o dużej gęstości, zanurzone lub znajdujące się na dnie. Kształt drobin wpływa na ich wchłanianie przez organizmy. Formy kuliste są częściej zjadane niż włókna. Cząstki o nieregularnym kształcie mogą powodować różne reakcje biochemiczne i fizjologiczne w organizmach żywych. Są też odpowiedzialne za wchłanianie zaadsorbowanych na powierzchni zanieczyszczeń organicznych, np. fenantrenu, który może kumulować się w przewodzie pokarmowym skorupiaków [4].

Obecność mikrocząstek tworzyw polimerowych w pobliżu wybrzeży morskich wynika z procesów degradacji i fragmentacji materiałów polimerowych (pod wpływem promieniowania UV, działania fal morskich, piasku i żwiru, mikroorganizmów) oraz ich transportu przez wiatr i prądy wodne. Degradacja polimerów syntetycznych w środowisku jest zwykle inicjowana przez fotooksydację (promieniowanie UV) lub hydrolizę [5]. Dominujący mechanizm zależy od rodzaju polimeru.

Podczas rozkładu polimeru zmniejsza się jego masa cząsteczkowa, a „uwolnione” wiązania są podatne na degradację mikrobiologiczną. Fotoutlenianie jest zwykle procesem szybkim, ale na jego przebieg duży wpływ ma skład tworzywa, głównie zawartość antyutleniaczy, które ograniczają proces utleniania. Fotodegradacja w środowisku wodnym zachodzi wolniej niż na lądzie [6]. Eksperymenty z rozpadem polietylenu i polistyrenu wykazały szybszą degradację tworzywa pływającego na powierzchni niż zanurzonego w wodzie, co prawdopodobnie było związane ze zmniejszonym natężenia światła, a tym samym z mniejszą szybkością fotoutleniania [7]. Dlatego wiele tworzyw polimerowych może pozostawać w środowisku wodnym przez dziesiątki lub setki lat.

Biodegradacja polimerów może zachodzić w środowisku tlenowym i beztlenowym, a rozkład do $\mathrm{CO}_{2}, \mathrm{H}_{2} \mathrm{O}$, $\mathrm{N}_{2}, \mathrm{H}_{2}, \mathrm{CH}_{4}$, soli mineralnych i biomasy (mineralizacja) może być całkowity lub częściowy. Częściowa degradacja łańcucha polimerowego prowadzi do stabilnych lub czasowo stabilnych produktów przemiany. Biodegradacja jest związana z trzema podstawowymi kryteriami:

Obecnością mikroorganizmów zdolnych do depolimeryzacji i mineralizacji związków polimerowych.

Warunkami środowiskowymi, takimi jak temperatura, pH, wilgotność i zasolenie, wpływającymi na przebieg procesu biodegradacji.

Strukturą chemiczną i fizyczną polimeru (wiązania chemiczne, stopień polimeryzacji, stopień rozgałęzienia, hydrofobowość, krystaliczność) umożliwiającą zasiedlanie przez mikroorganizmy i tworzenie biofilmu [8].

Około 80-85\% odpadów na europejskich plażach stanowią tworzywa polimerowe, połowa z nich to artykuły jednorazowego użytku. Badania próbek wód z Morza Północnego i Bałtyku potwierdziły obecność na mikrocząstkach polimerów drobnoustrojów Vibrio parahaemolyticus [9]. Ich nadmierny rozwój może zagrozić populacji krewetek.

Mikroplastik może być wchłaniany przez organizmy morskie. Znaleziono go m.in. w skorupiakach i mię- 


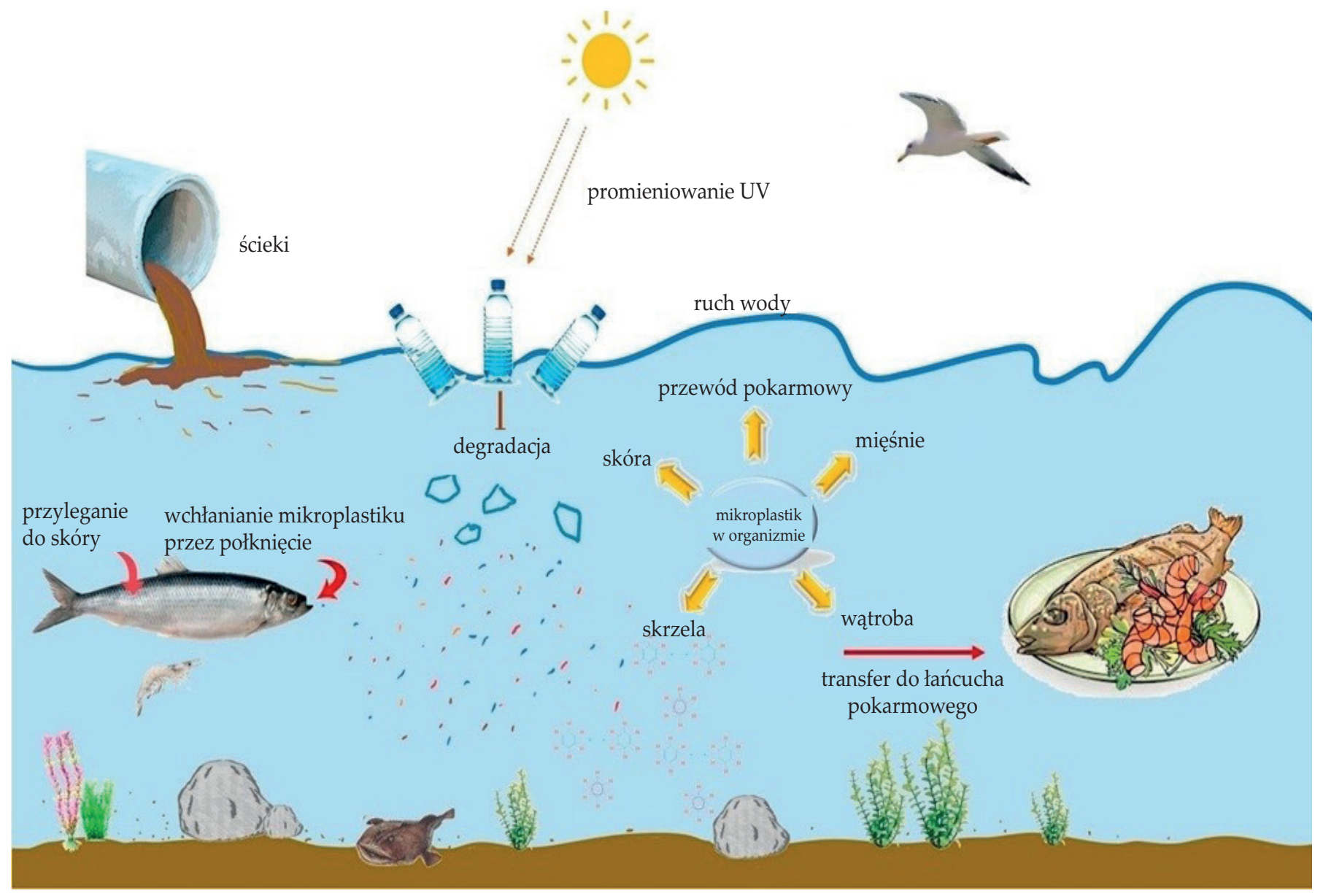

Rys. 1. Akumulacja mikroplastiku w środowisku morskim

Fig. 1. Accumulation of microplastics in the marine environment

(Źródło: Marine Pollution Bulletin Volume 131, Part A, June 2018)

czakach. Na rys. 1 pokazano migrację mikroplastiku w wodzie morskiej.

Część odławianych ryb wykorzystywana jest do produkcji pasz dla zwierząt hodowlanych, co dodatkowo zwiększa obszar skażenia mikroplastikiem. Obecność mikroplastiku wykryto również $\mathrm{w}$ wielu produktach spożywczych, takich jak: piwo, woda pitna [10], miód, cukier [11], sól [12]. Poprzez łańcuchy pokarmowe mikroplastik może dostać się do organizmu człowieka. Długotrwałe narażenie na spożycie mikrocząstek polimeru, nawet przy małym stężeniu, stanowi potencjalne zagrożenie dla zdrowia ludzi.

Także w powietrzu, z drobinami kurzu unoszą się włókna mikroplastiku, które mogą przedostawać się do płuc lub osiadać na produktach spożywczych.

Badania przeprowadzone przez Instytut Roberta Kocha w Niemczech pokazały, że w 97\% próbek krwi i moczu dzieci w wieku od 3 do 17 lat znajduje się mikroplastik [13].

Natomiast badania wykonane z inicjatywy WWF przez Uniwersytet w Newcastle w Australii udowodniły, że do organizmu ludzkiego trafia do $5 \mathrm{~g}$ mikroplastiku tygodniowo [14].
Mikroplastik powstający w gospodarstwie domowym (zużywanie się ubrań i przedmiotów z tworzyw polimerowych, używanie kosmetyków i chemii gospodarczej) poprzez kanalizację przedostaje się do rzek, a następnie do mórz i oceanów.

Wraz z mikroplastikiem do środowiska naturalnego mogą uwalniać się obecne $\mathrm{w}$ tworzywach małocząsteczkowe substancje pomocnicze (plastyfikatory, barwniki, modyfikatory). Mała masa cząsteczkowa (poniżej $600 \mathrm{~g} / \mathrm{mol}$ ) zwiększa ich podatność na migrację do środowiska. Szybkość migracji zależy od szybkości procesu starzenia tworzywa oraz warunków atmosferycznych. Substancje wprowadzane do tworzyw polimerowych (obecnie zabronione), takie jak ftalany, PBDE (polibromowane difenyloetery), PFOA (kwas perfluoooktanowy), BPA (bisfenol A), barwniki zawierające ołów lub kadm są klasyfikowane jako substancje niebezpieczne [15].

Obecność mikroplastiku wpływa na degradację środowiska naturalnego, powodując ograniczenie wzrostu i zdolności reprodukcyjnych organizmów żywych, a nawet ich śmierć. Jednak $\mathrm{w}$ dalszym ciągu jest za mało badań potwierdzających ścisłą zależność pomiędzy mikroplastikiem a bezpieczeństwem żywności. 
Tabela 1. Stężenie mikroplastiku oraz rodzaj tworzywa w osadach przybrzeżnych [16-21]

Table 1. The concentration of microplastics and type of polymer in coastal sediments

\begin{tabular}{l|c|c|c|c}
\hline \multicolumn{1}{c|}{ Lokalizacja } & $\begin{array}{c}\text { Liczba cząstek/ } \\
\text { kg suchej masy }\end{array}$ & $\begin{array}{c}\text { Wielkość } \\
\text { cząstek }\end{array}$ & Rodzaj tworzywa & Metoda oznaczenia \\
\hline Portugalia, Algarve, wybrzeże & 10 & $>1 \mu \mathrm{m}$ & $\begin{array}{c}\text { PP, Rayon (sztuczny } \\
\text { jedwab) }\end{array}$ & Mikroskop + FTIR \\
$\begin{array}{l}\text { Portugalia, wybrzeże zachodnie, } \\
\text { plaża }\end{array}$ & 29 & $<1 \mu \mathrm{m} ;>10 \mu \mathrm{m}$ & PE, PS, PL & Mikroskop + FTIR \\
$\begin{array}{l}\text { Belgia, Morze Północne, plaża } \\
\text { Polska, Bałtyk, linia brzegowa }\end{array}$ & $93-167$ & $38 \mu \mathrm{m}-1 \mathrm{~mm}$ & PA, PE, PP, PS, PVA & Mikroskop +FTIR \\
Taiwan, wybrzeże północne & 53 & $0,1-5 \mathrm{~mm}$ & PE, PP, PVAc & Mikroskop + FTIR \\
Urugwaj, Punta del Este, plaża & 55 & $0,25 \mathrm{~mm} \geq 4 \mathrm{~mm}$ & ABS, PE, PP, PS & FTIR \\
\hline
\end{tabular}

PP - polipropylen, PE - polietylen, PS - polistyren, PL - poliester, ABS - kopolimer akrylonitryl-butadien-styren, PVAc - poli(octan winylu), PVA - poli(alkohol winylowy), PVC - poli(chlorek winylu), PET - poli(tereftalan etylenu).

T a b e 1 a 2 . Stężenie mikroplastiku oraz rodzaj tworzywa w słupie wody na obszarach przybrzeżnych [22-27]

$\mathrm{T}$ a b l e 2. The concentration of micorplastics and type of polymer in the water column of coastal areas

\begin{tabular}{|c|c|c|c|c|}
\hline Lokalizacja & Liczba cząstek $/ \mathrm{m}^{3}$ & $\begin{array}{l}\text { Wielkość } \\
\text { cząstek }\end{array}$ & Rodzaj tworzywa & Metoda oznaczenia \\
\hline Japonia, Morze Wewnętrzne & 0,4 & $0,1 \mathrm{~mm} ;>10 \mathrm{~mm}$ & PE, PP & FTIR \\
\hline Chiny, południowe ujścia rzek & $100-4100$ & $0,5-5 \mathrm{~mm}$ & PE, PP, PTFE, PVC & $\begin{array}{c}\text { Mikroskop + } \\
\text { spektroskopia Ramana }\end{array}$ \\
\hline Hong Kong, wody przybrzeżne & $0,5-280$ & $0,03-5 \mathrm{~mm}$ & PE, PP, SA & FTIR \\
\hline $\begin{array}{l}\text { Francja, Belgia, Holandia, } \\
\text { wybrzeże Morza Północnego }\end{array}$ & 400 & $30-300 \mu \mathrm{m}$ & PS & $\begin{array}{c}\text { Mikroskop + } \\
\text { spektroskopia Ramana }\end{array}$ \\
\hline Brazylia, Zatoka Jurujuba & 16 & $<1 \mathrm{~mm} ; \geq 5 \mathrm{~mm}$ & PE, PP & FTIR \\
\hline Australia, wody przybrzeżne & $0,01-0,05$ & $0,4-82 \mathrm{~mm}$ & EVA, PE, PS & FTIR \\
\hline
\end{tabular}

PE - polietylen, PP - polipropylen, PS - polistyren, SA kopolimer styren-akrylonitryl, PTFE - poli(tetrafluoroetylen), PVC - poli(chlorek winylu), EVA - kopolimer etylen-(octan winylu).

Próbki pobierano z głębokości 2-75 cm od lustra wody.

W tabelach 1 i 2 przedstawiono stężenie mikroplastiku w osadach wodnych i w wodzie morskiej w zależności od obszaru występowania.

\section{ANALIZA MIKROPLASTIKU}

Aktualnie nie ma ujednoliconych metod analizy mikroplastiku. Do identyfikacji mikrocząstek tworzyw polimerowych służą metody fizyko-chemiczne, głównie techniki mikroskopowe (SEM), spektroskopowe (FTIR, spektrometria Ramana), termiczne (TGA, DSC) i chromatograficzne (GC, HPLC). Obiecujące wyniki uzyskano poprzez połączenie różnych technik pomiarowych, np. termograwimetrii z różnicową kalorymetrią skaningową (TGA-DSC), pirolizy z chromatografią gazową i spektrometrią mas (Py-GC-MS) oraz chromatografii gazowej z desorpcją termiczną i spektrometrią mas (TED-GC-MS). W analityce polimerów powszechnie stosowane są metody termiczne. Układ Py-GC-MS może dostarczyć informacji nie tylko o polimerze, ale także o zastosowanych środkach pomocniczych [28].

Metody spektroskopowe pozwalają na badanie struktury polimeru poprzez porównanie widm absorpcyjnych i emisyjnych $z$ widmami referencyjnymi. Mikroskop sprzężony ze spektrometrem Ramana umożliwia identyfikację cząstek o średnicy od 1 do $20 \mu \mathrm{m}$, a w przypadku spektrofotometru FTIR cząstek o wielkości od 10 do $20 \mu \mathrm{m}$.

Procedury analityczne wymagają jednak czystych próbek, gdyż zanieczyszczenia mogą zafałszować wynik pomiaru.

\section{AKTY PRAWNE}

Unia Europejska widząc potrzebę sprostania wyzwaniom związanym z tworzywami polimerowymi, opracowała strategię gospodarki o obiegu zamkniętym (GOZ). GOZ jest koncepcją wg której produkty, materiały i surowce mają pozostawać $\mathrm{w}$ gospodarce tak długo, jak jest to możliwe. W komunikacie UE z dnia 16 stycznia 2018 r. komisja UE stwierdza, że strategia na rzecz gospodarki o obiegu zamkniętym, w całym cyklu życia tworzyw polimerowych, musi polegać na ograniczeniu generowania coraz większej ilości odpadów oraz na zapobieganiu przedostawaniu się ich do środowiska, głównie morskiego. Wg koncepcji GOZ na każdym etapie wytwarzania wyrobów z tworzyw (projektowanie, produkcja) powinny być uwzględnione możliwości ponownego ich użycia, naprawy lub recyklingu. Wytwarzane 
materiały powinny być zrównoważone, nietoksyczne i przeznaczone do wielokrotnego użycia.

Dyrektywa 94/62/WE Parlamentu Europejskiego w sprawie opakowań i odpadów opakowaniowych kładzie nacisk na działania proekologiczne. Dyrektywa ta wskazuje na sposób zapobiegania powstawaniu odpadów opakowaniowych i możliwości ich ponownego wykorzystania, recyklingu materiałowego, chemicznego i energetycznego lub biodegradacji. Dyrektywa nie zaleca składowania odpadów. Dyrektywa (UE) 2015/720, nowelizująca dyrektywę 94/62/WE, narzuca państwom członkowskim ograniczenia zużycia "lekkich toreb na zakupy”, które stanowią ogromny problem środowiskowy [29].

Komisja Europejska zakłada, że do 2030 r. wszystkie opakowania z tworzyw będą nadawały się do recyklingu. Od 3 lipca 2021 r. obowiązuje dyrektywa Parlamentu Europejskiego i Rady (EU) 2019/904 tzw. dyrektywa SUP (Single Use Plastics) [30]. Celem tej dyrektywy jest ograniczenie użycia wyrobów jednorazowych, przeznaczonych do użycia w krótkim czasie, które wyrzucane, zaśmiecają środowisko naturalne. Narzędziem mającym pomóc $\mathrm{w}$ ograniczeniu mikroplastiku $\mathrm{w}$ środowisku wodnym jest dyrektywa Parlamentu Europejskiego i Rady (UE) 2020/2184 [31]. Głównym jej celem jest poprawa dostępności bezpiecznej wody pitnej. Jest ona odpowiedzią na rosnące obawy, jakie budzi wpływ na zdrowie ludzkie obecność w wodzie pitnej substancji zaburzających gospodarkę hormonalną takich jak farmaceutyki i mikroplastik.

W 2019 r. Europejska Agencja Chemikaliów ECHA opublikowała propozycję ograniczeń stosowania tworzyw polimerowych w produktach kosmetycznych, które mogą być potencjalnym źródłem mikroplastiku pierwotnego. Dokument ECHA zawiera listę 19 takich polimerów. Obecnie niektóre firmy kosmetyczne świadome zagrożeń, $\mathrm{w}$ trosce o dobro konsumenta, wyeliminowały znajdujące się na tej liście polimery ze składu swoich produktów [32].

Niezmiernie ważną inicjatywą państw członkowskich Unii Europejskiej jest Morska Dyrektywa Ramowa (MSFD), która wymaga monitorowania zanieczyszczeń w środowisku morskim. Dyrektywa ta ma na celu osiągnięcie „, dobrego stanu środowiska" do $2028 \mathrm{r}$.

W 2018 r. Komisja Europejska utworzyła mechanizm doradztwa naukowego (SAM), który wspierany przez konsorcjum SAPEA (Science Advice for Policy by European Academies) dostarcza danych dotyczących wpływu mikrozanieczyszczeń na środowisko naturalne i zdrowie człowieka. Wniosek wynikający z działalności tej grupy pokazuje, że w niektórych obszarach wód przybrzeżnych istnieje już zagrożenie ekologiczne [33].

\section{PODSUMOWANIE}

Zanieczyszczenie mikroplastikiem stanowi zagrożenie dla środowiska. Badania wykazały obecność mikrocząstek plastiku w mikroorganizmach i produktach spożywczych. Prowadzone są intensywne badania wpływu mikropla- stiku na zdrowie człowieka. Doskonalone są techniki monitorowania zanieczyszczeń, pobierania próbek oraz walidacji stosowanych metod analitycznych. Najczęściej stosowane są techniki oparte na spektrometrii (Ramana, FTIR), chromatografii (GC/MS) oraz analizie termicznej (TGA, DSC). Działania podejmowane w celu ograniczenia odpadów polimerowych w środowisku naturalnym wychodzą naprzeciw rosnącemu zainteresowaniu opinii publicznej wpływem występujących w wodzie pitnej i żywności zanieczyszczeń na zdrowie ludzi i zwierząt.

\section{LITERATURA}

[1] Nałęcz M.: Opakowanie, 2019, 12, 20.

[2] Food and Agriculture Organization of the United Nations, FAO, 2017.

[3] EFSA Journal, adopted: 11 May 2016, Presence of microplastics and nanoplastics in food, with particular focus on seafood EFSA Panel on Contaminants in the Food Chain (CONTAM). https://doi.org/10.2903/j.efsa.2016.4501

[4] Hantoro I., Lohr Ansje J., Van Belleghemrank F.G.A.J et al:: Food Additives \& Contaminants: Part A 2019, 36(5), 674. https://doi.org/10.1080/19440049.2019.1585581

[5] Andrady A.L.: Marine Pollution Bulletin 2011, 62(8), 1596.

https://doi.org/10.1016/j.marpolbul.2011.05.030

[6] Andrady AL, Pegram JE, Song Y.: Journal of Polymers and the Environment 1993, 1(2),117. https://doi.org/10.1007/BF01418205

[7] Leonas KK, Gorden RW.: Journal of Polymers and the Environment 1993, 1(1), 45. https://doi.org/10.1007/bf01457652

[8] Grima S., Bellon-Maurel V., Feuilloley P., Silvestre F.: Journal of Polymers and Environment 2000, 8(4), 183. https://doi.org/10.1023/A:1015297727244

[9] Kirstein I.V., Kirmizi S., Wichels A. et al.: Marine Environmental Research, 2016, 120, 1. https://doi.org/10.1016/j.marenvres.2016.07.004

[10] Kosuth M., Mason S.A., Wattenberg E.V.: PLOS ONE 2018. https://doi.org/10.1371/journal.pone.0194970

[11] Liebezeit G., Liebezeit E., Food Additives \& Contaminants: Part A 2013, 30(12), 2136. https://doi.org/10.1080/19440049.2013.843025

[12] Renzi M, Blašković A.: Marine Pollution Bulletin 2018, $135,62$. https://doi.org/10.1016/j.marpolbul.2018.06.065

[13] https://naukawpolsce.pap.pl/aktualnosci/news$\% 2$ C $78619 \% 2$ Cbadanie-niepokojaca-iloscchemikaliow-z-plastiku-w-organizmach-dzieci. $\mathrm{html}$ [dostęp w internecie 12.10.2021]

[14] https://www.newcastle.edu.au/newsroom/ featured/plastic-ingestion-by-people-could-beequating-to-a-credit-card-a-week/how-much-microplastics-are-we-ingesting-estimation-of-the- 
mass-of-microplastics-ingested [dostęp w internecie 27.10.2021]

[15] "Microplastics in drinking-water", World Health Organization 2019, ISBN 978-92-4-151619-8.

[16] Frias J.P.G.L., Gago J., OteroV., Sobral P.: Marine Environmental Research 2015, 114, 24.

https://doi.org/10.1016/j.marenvres.2015.12.006

[17] MartinsJ., Sobral P. Marine Pollution Bulletin 2011, 12, 2649.

https://doi.org/10.1016/j.marpolbul.20.11.09.028.

[18] Claesses M., De Meester S., Van Landut L. et al.: Marine Pollution Bulletin 2011, 62, 2199. https://doi.org/10.1016/j.marpolbul.2011.06030

[19] Graca B., Szewc K., Zakrzewska D. et al.: Environmental Science and Pollution Research 2017, 24, 7650. http://link.springer.com/10.1007/s11356-017-8419-5

[20] Kunz A., Walther B.A., Lowemark L., Lee Y.C.: Marine Pollution Bulletin 2016, 111, 126. https://doi.org/ 10.1016/j.marpolbul.2016.07.022

[21] Lozoya J.P., de Mello F., Carrizi D. et al.: Environmental Pollution 2016, 218, 931. https://doi.org/10.1016/j.envpol.2016.08.0410269-7491

[22] Isobe A., Kubo K., Tamura Y. et al.: Marine Pollution Bulletin 2014, 89, 324. https://doi.org/10.1016/j.marpolbul.2014.09.041

[23] Zaho S., Zhu L., Li D.: Enviromental Pollution 2015, 206, 5797. https://doi.org/10.1016/ 2015.08.027

[24] Tsang Y.Y., Mak C.W., Liebich C. et al.: Marine Pollution Bulletin 2016, 115, 20. https://doi.org/ 10.1016/j.marpolbul.2016. 11.003
[25] Van Cauwenberghe L., Claessens M., Vandegehuchte MB., Janssen CR.: Environmental Pollution 2015, 199C, 10. https://doi.org/10.1016/j.envpol.2015.01.008

[26] Castro R.O., Silva M.L., Regina M. et al.: Marine Pollution Bulletin 2016, 110, 555. https://doi.org/ 10.1016/j.marpolbul.2016.05.037

[27] Reisser J., Show J., Wilcox C. et al.: PLOS.ONE Project: Plastic pollution in the world's oceans 2013, 8. https://doi.org/10.1371/journal.pone.0080466

[28] Klein S, Dimzon IK, Eubeler J, Knepper TP. „Freshwater Microplastics: Emerging Environmental Contaminants?" The Handbook of Environmental Chemistry 58, Springer International Publishing, 2018, 51.

[29] Dyrektywa Parlament Europejskiego i Rady (UE) 2015/720 z dnia 29 kwietnia 2015 r. zmieniająca dyrektywę 94/62/WE w odniesieniu do zmniejszenia zużycia lekkich plastikowych toreb na zakupy.

[30] Dyrektywa Parlamentu Europejskiego i Rady (UE) 2019/904 z dnia 5 czerwca 2019 r. w sprawie zmniejszenia wpływu niektórych produktów z tworzyw sztucznych na środowisko.

[31] Dyrektywa Parlamentu Europejskiego i Rady (UE) 2020/2184 z dnia 16 grudnia 2020 r. w sprawie jakości wody przeznaczonej do spożycia przez ludzi.

[32] Wiąckowska M.: Świat przemysłu kosmetycznego 2020, 3,44 .

[33] Pavlo A., Anklam E., Emans T. et al.: Food Additives \& Contaminants: Part A, 2019, 37(1). https://doi.org/10.1080/19440049.2019.1673905

Otrzymano 26 XI 2021 r.

\section{Rapid Communications}

Przypominamy Autorom, że publikujemy artykuły typu Rapid Communications - prace oryginalne wyłącznie w języku angielskim (o objętości 4-5 stron maszynopisu z podwójną interlinią, zawierające 2-3 rysunki lub 1-2 tabele), którym umożliwiamy szybką ścieżkę druku (do 3 miesięcy od chwili ich otrzymania przez Redakcję). Artykuł należy przygotować wg wymagań redakcyjnych zamieszczonych we wskazówkach dla P.T. Autorów.

We remind Authors that we publish articles of the Rapid Communications type - the original papers, in English only (with a volume of 4-5 pages of double-spaced typescript, containing 2-3 figures or 1-2 tables), which allow a fast print path (up to 3 months from when they are received by the Editorial Board). The article should be prepared according to the editorial requirements included in the Guide for Authors. 